parameters were analysed during 6 months of follow-up after starting anticoagulation therapy with acenocoumarol.

Results One hundred and eighteen patients (mean age: $73 \pm 12$ years; $55.7 \%$ male) treated with acenocoumarol therapy and monitored for dose adjustment were recruited.

The frequency of different genotypes according to stable anticoagulation status is shown in Table 1 . Table 2 shows the frequency of genotypes in stable anticoagulated patients classified by stable anticoagulation dose (High: $>28 \mathrm{mg} /$ week; Intermediate: 7-28 mg/ week; Low dose: $<7 \mathrm{mg}$ /week).

The stable anticoagulation status was not associated to any gene polymorphism, and the stable anticoagulation dose was only associated to CYP2C9*3 (0.047).

Conclusions The achievement of a stable anticoagulation status is not associated to VKORC1, CYP2C9*2, CYP4F2*2, CYP2C19*17 or MDR1-C3435T gene polymorphisms, although the stable anticoagulation dose is associated to CYP2C9*3.

Abstract DGI-68 Table 1 The frequency of different genotypes according to stable anticoagulation status

\begin{tabular}{|c|c|c|c|c|c|c|}
\hline \multirow[b]{2}{*}{ Gene polymorphism } & \multirow[b]{2}{*}{ Genotype } & \multirow[b]{2}{*}{$\mathbf{n}$} & \multicolumn{2}{|c|}{ Stable } & \multirow[t]{2}{*}{ Total } & \multirow[t]{2}{*}{ p-value } \\
\hline & & & No & Yes & & \\
\hline \multirow[t]{3}{*}{ VKORC1*2 (rs9923231) } & CC & 44 & 30 & 14 & 115 & 0.758 \\
\hline & СТ & 57 & 40 & 17 & & \\
\hline & TT & 14 & 11 & 3 & & \\
\hline \multirow[t]{3}{*}{ CYP2C9*2 (rs1799853) } & CC (WT) & 82 & 61 & 21 & 117 & 0.223 \\
\hline & CT & 33 & 20 & 13 & & \\
\hline & $\pi$ & 2 & 2 & 0 & & \\
\hline \multirow{2}{*}{ CYP2C9*3 (rs1057910) } & AA (WT) & 98 & 69 & 29 & 116 & 0.724 \\
\hline & $A C$ & 18 & 14 & 4 & & \\
\hline \multirow[t]{3}{*}{ CYP4F2*3 (rs2108622) } & CC (WT) & 53 & 38 & 15 & 117 & 0.352 \\
\hline & CT & 50 & 33 & 17 & & \\
\hline & $\pi$ & 14 & 12 & 2 & & \\
\hline \multirow[t]{3}{*}{ CYP2C19*17 (rs12248560) } & GG (WT) & 85 & 59 & 26 & 113 & 0.729 \\
\hline & GA & 27 & 20 & 7 & & \\
\hline & AA & 1 & 1 & 0 & & \\
\hline \multirow[t]{3}{*}{ АВСВ1 С3435T (rs1045642) } & CC (WT) & 31 & 22 & 9 & 118 & 0.864 \\
\hline & CT & 56 & 41 & 15 & & \\
\hline & $\pi$ & 31 & 21 & 10 & & \\
\hline
\end{tabular}

VKORC1: Vitamin k epoxide reductase complex,subunit 1; CYP2C9*2: Cytochrome P450 family 2, subfamily C, polypeptide 9, allele variant:2; CYP2C9*3 Cytochrome P450 family 2, subfamily C, polypeptide 9, allele variant: 3; CYP4F2: cytochrome P450, family 4, subfamily F, polypeptide 2; CYP2C19 Cytochrome P450 family 2 subfamily C,polypeptide1 9;ABCB1: ATP-binding cassette, subfamily B, member 1 .

Abstract DGI-068 Table 2 The frequency of genotypes in stable anticoagulated patients classified by stable anticoagulation dose

\begin{tabular}{lllllll}
\hline & & & Low & Intermediate & High & \\
Gene polymorphism & Genotype & Stable & dose & dose & dose & p-value \\
\hline VKORC1*2 (rs9923231) & CC & 13 & 0 & 13 & 1 & 0.280 \\
& CT & 17 & 1 & 15 & 1 & \\
& TT & 3 & 1 & 2 & 0 & \\
CYP2C9*2 (rs1799853) & CC (WT) & 21 & 1 & 18 & 2 & 0.498 \\
& CT & 13 & 1 & 12 & 0 & \\
CYP2C9*3 (rs1057910) & AA (WT) & 29 & 1 & 27 & 1 & 0.047 \\
& AC & 4 & 1 & 2 & 1 & \\
CYP4F2*3 (rs2108622) & CC (WT) & 15 & 1 & 14 & 0 & 0.685 \\
& CT & 17 & 1 & 14 & 2 & \\
CYP2C19*17 (rs12248560) & TT & 2 & 0 & 2 & 0 & \\
& GG (WT) & 26 & 2 & 22 & 2 & 0.542 \\
ABCB1 C3435T (rs1045642) & GC & 7 & 0 & 7 & 0 & \\
& CT (WT) & 9 & 1 & 8 & 0 & 0.430 \\
& TT & 15 & 1 & 12 & 2 & \\
\hline
\end{tabular}

(High dose: > 28 mg/week; Intermediate dose: 7-28 mg/week; Low dose: <7 mg/week)

No conflict of interest.

\section{DGI-069 THE IMPORTANCE OF CLINICAL PHARMACIST COUNSELLING IN IMPROVING PATIENT MEDICATION ADHERENCE}

doi:10.1136/ejhpharm-2013-000276.335

A Carollo, A Adamo, C Di Giorgio, P Polidori. ISMETT, Clinical Pharmacy, Palermo, Italy

Background Adherence is a key factor in achieving good clinical outcomes in patients undergoing long-term treatment. Meeting with patients is fundamental in educating them on correct drug use, and recommending dietary and lifestyle changes.

Purpose To assess the clinical pharmacist (CP) counselling programme, up to the discharge and outpatient visits, to improve medicines adherence, reduce adverse drug events, and encourage positive behaviour.

Materials and Methods CP counselling was addressed to adult abdominal and cardiac surgery patients, including transplanted patients. The topics discussed were: importance of prescribed drugs and therapeutic indications, directions, and potential side effects. A drug information sheet was given to all patients. A survey was then conducted by the ISMETT Pharmacy Service from 1 May to 30 September 2012.

Results The survey included 524 patients, of whom $54.6 \%$ were transplant patients and $45.4 \%$ cardiology patients; 326 were male and 198 female, with a mean age of $56 \pm 15.1$. Of these patients, $97.5 \%(511 / 524)$ knew that respecting therapeutic recommendations improves outcomes and $85.3 \%(447 / 524)$ reported that the CP had explained the importance of correct dosage and mode of administration. However $11.5 \%(60 / 524)$ didn't know the correct mode of administration and $6.3 \%(33 / 524)$ didn't take their drugs on time. $4.8 \%(25 / 524)$ reported occasionally missing a dose, $32 \%$ of them $(8 / 25)$ because of a lack of symptoms, and $68 \%(17 / 25)$ because of a regimen of multidrug treatment. CP counselling was repeated for patients who didn't completely adhere to treatment. For clinical reasons and to increase patient compliance, the physician and $\mathrm{CP}$ changed the treatment from mycophenolate mofetil to mycophenolic acid for 7 patients, from immediate release tacrolimus to an extended release formulation for 1 , and from mycophenolate mofetil to everolimus for 1 . All patients reported that CP counselling had a positive effect and $58.6 \%$ asked to meet with the CP more often.

Conclusions Our survey confirmed that CP counselling improves patient outcomes and safety, results in stricter adherence to treatment and changes in patient behaviour, and contributes to better outcomes and faster convalescence.

No conflict of interest.

\section{DGI-070 THE PURPLE WASTE STREAM - HOW NORTH BRISTOL NHS TRUST (NBT) DEALS WITH HAZARDOUS WASTE MEDICINES}

doi:10.1136/ejhpharm-2013-000276.336

S Fradgley, JB Smith. North Bristol NHS Trust, Pharmacy, Bristol, UK

Background All hazardous pharmaceutical waste must be clearly identified, segregated and consigned with the six digit European Waste Catalogue code (18 0108 ) within purple-lidded containers to permit safe destruction. [The Hazardous Waste (England and Wales) Regulations 2005 (amended 2009)].

Within NBT, as for most UK hospitals, the route for the disposal of cytotoxic pharmaceutical waste was well established, but did not include cytostatic material.

Purpose To adopt a new mechanism throughout NBT to:

- Identify and segregate hazardous waste

- Raise awareness and train staff to manage waste legally

- Introduce new hazardous labelling and patient information 